\title{
FRACTOGRAPHIC STUDY OF MARINE DIESEL ENGINE CONNECTING ROD STUD BOLT CRACK
}

\author{
K. Carjova*, V. Priednieks, R. Klaucans, I. Irbe, A. Urbahs \\ Latvian Maritime Academy, \\ 12 k-1 Flotes Str., Riga, LV-1016, LATVIA \\ *e-mail: kristine.carjova@latja.Iv
}

Failures of marine diesel engine components can lead to serious consequences for a vessel, cargo and the people on board a ship. These consequences can be financial losses, delay in delivery time or a threat to safety of the people on board. This is why it is necessary to learn about connecting rod bolt failures in order to prevent worst-case scenarios.

This paper aims at determining the origin, velocity and the duration of fatigue crack development of a diesel alternator engine which suffered a significant failure of one of its mains, not long after a major overhaul had been completed and with less than 1000 running hours having elapsed.

It was verified with fatigue rupture of one of the four connecting rod stud bolts. Tensile tests were performed in the remaining connecting rod bolts. During this procedure, another fatigue crack in an adjacent bolt was identified. The probable root case of damage, and at the end some final remarks are presented.

Keywords: Acoustic emission, connecting rod, crack, diagnostics, fatigue crack growth rate, fractography, fatigue test, marine diesel engine failure.

\section{INTRODUCTION}

The power generated by the piston in the combustion chamber of marine engine is transferred to the crankshaft using the connecting rod. While transferring this tremendous power, the connecting rod itself is subject to different stresses, which make is vulnerable to damage. For this reason, the connecting rod bolts are used to join the connecting rod and con-rod bearing cover under the tremendous stresses 
generated by the running engine.

The most common type of connecting rod that is used in the ship auxiliary engine is oblique or crosscut connecting rod, which is made of two parts.

The connecting rod of the engine must be inspected at regular intervals of time to ensure there is no defect or problem to avoid any future accidents/emergency [1], [2] .

The studies of how bolting assemblies are influenced by fatigue are presented below. In engineering, bolted connections are employed in a very large number of structural members. These connections may look simple on the surface level, but are complex assembles with varying geometric and fatigue properties, which need to be properly accounted for in order to provide a clear picture of their useful life in service. An introduction into fatigue and methods by which fatigue strength can be quantified are examined in the present paper.

The aim of the research is to examine the fatigue and crack propagation of the rod bolt or to find the effect of other destructive forces that cause the engine to collapse.

\section{CASE STUDY}

Significant damage of ships machinery, which happened not long after major overhaul had been completed and with less than 1000 running hours having elapsed, resulted in financial loss and insurance attention. In order to restore the engine and the vessel back to full operating capacity, replacement of the complete engine frame as well as a new crankshaft, along with other major components were required.

Study of diesel engine stud bolt resulted in fatigue crack after 39596 cycles of the bench operating time in resource test program were reached. Loading modes were determined according to the engine rotation speed.

The basic causes of failure were due to the fact that tensioning procedures and elongation checks for hydraulic bolts were not properly followed and re-tensioning checks were not done according to manufacturer instruction manual or with reference to engine technical service letters.
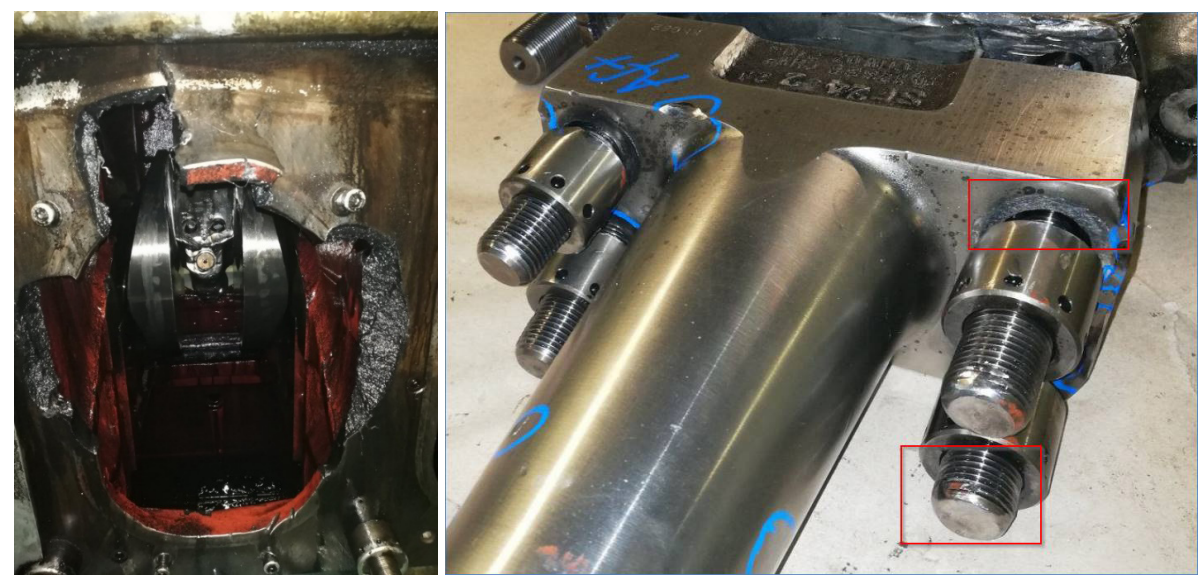

Fig. $1 \& 2$. Damaged engine frame and connecting rod. 
Two of the fractured bolts and bolts from the remaining connecting rods were selected for laboratory analysis. The analyses consisted of low magnification and scanning electronic microscopy (by scanning with a SEM HITACHI-S300 N scanning electron microscope) observation of the fracture surface, hardness, tensile tests and metallographic characterisation. Hardness was performed over the flat shank of some selected bolts using the Rockwell C scale (HRC). Tensile tests were performed with MTS 810 (MTS Corporation, Eden Prairie, $\mathrm{MN})$. Metallographic analyses were done in two selected bolts: one broken during the failure, other during the tensile test.

\section{DEFECT MECHANISM AND MATHEMATICAL MODEL DESIGNATIONS}

Fatigue can be defined as a process of damage accumulated during each cycle of the dynamic load that the structure is subjected to with an important characteristic of load intensity lower than the values that would cause immediate failure [3]. Fatigue cracks start and evolve in two phases - formation (usually starting on the material surface) of a shear crack on crystallographic slip planes in the first phase, and growth of the crack in a direction normal to the applied stress in the second phase [4]. Cui proposed a division of the failure fatigue process in five stages, namely, crack nucleation, microstructurally small crack propagation, physically small crack propagation, long crack propagation and final fracture [5].

Many crack propagation equations have been proposed over the years to improve prediction accuracy and incorporate a variety of effects. The general form of these crack propagation equations may be expressed as:

$\frac{d L}{d N}=f\left(\Delta \sigma, L \cdot c_{i}\right)$,

where, the crack length is denoted by L, $\mathrm{mm}$, which is measured from the source of fatigue failure in the selected direction of propagation of the crack perpendicular to its front. The number of cycles of load applied is given by $\mathrm{N}$, loading cycles: bench operating hours (in the calculations the operating time of the last day of testing is used); $\Delta \sigma$ is the stress range and $c_{i}$-the material parameters.

Designations that are used further in the paper:

$V_{\mathrm{L}}, \mu /$ cycle 1 - the crack growth rate, which is measured in increment of crack length per loading cycle.

$\mathrm{h}, \mathrm{nm} /$ cycle - the fatigue damage mesoline pitch in one cycle.

$\Delta \mathrm{N}_{\mathrm{CRi}}$, loading cycles - the number of loading cycles during which the crack grew from the minimum analysed size to the current value of its length, at which the rate of crack growth $V_{\mathrm{L}}$ was measured by the size of mesoline pitch h, $\mu$ (nm) (in the calculations, the bench operating time was used last day of testing).

$\mathrm{N}_{\mathrm{CR}}$, loading cycles - the number of loading cycles during which the crack grew from the minimum size to the current value of its length, at which the crack growth rate $V_{\mathrm{Li}}, \mathrm{nm} /$ cycle $(\mu /$ cycle) was measured by the mesoline pitch (in calculations, the operating time of the last test day is used). 
Crack growth equations of the form are not a true differential equation, as they do not model the process of crack growth in a continuous manner throughout the loading cycle. Separate cycle counting or identification algorithms, such as the commonly used rain flow-counting algorithm, are required to identify the maximum and minimum values in a cycle. Although developed for the stress/strain-life methods, rain flow counting has also been shown to work for crack growth [6].

\section{FRACTOGRAPHIC STUDY RESULTS}

A fractographic study of fracture of the fracture of the bolt is shown in Fig. 3. stud bolt was carried out. A general view of

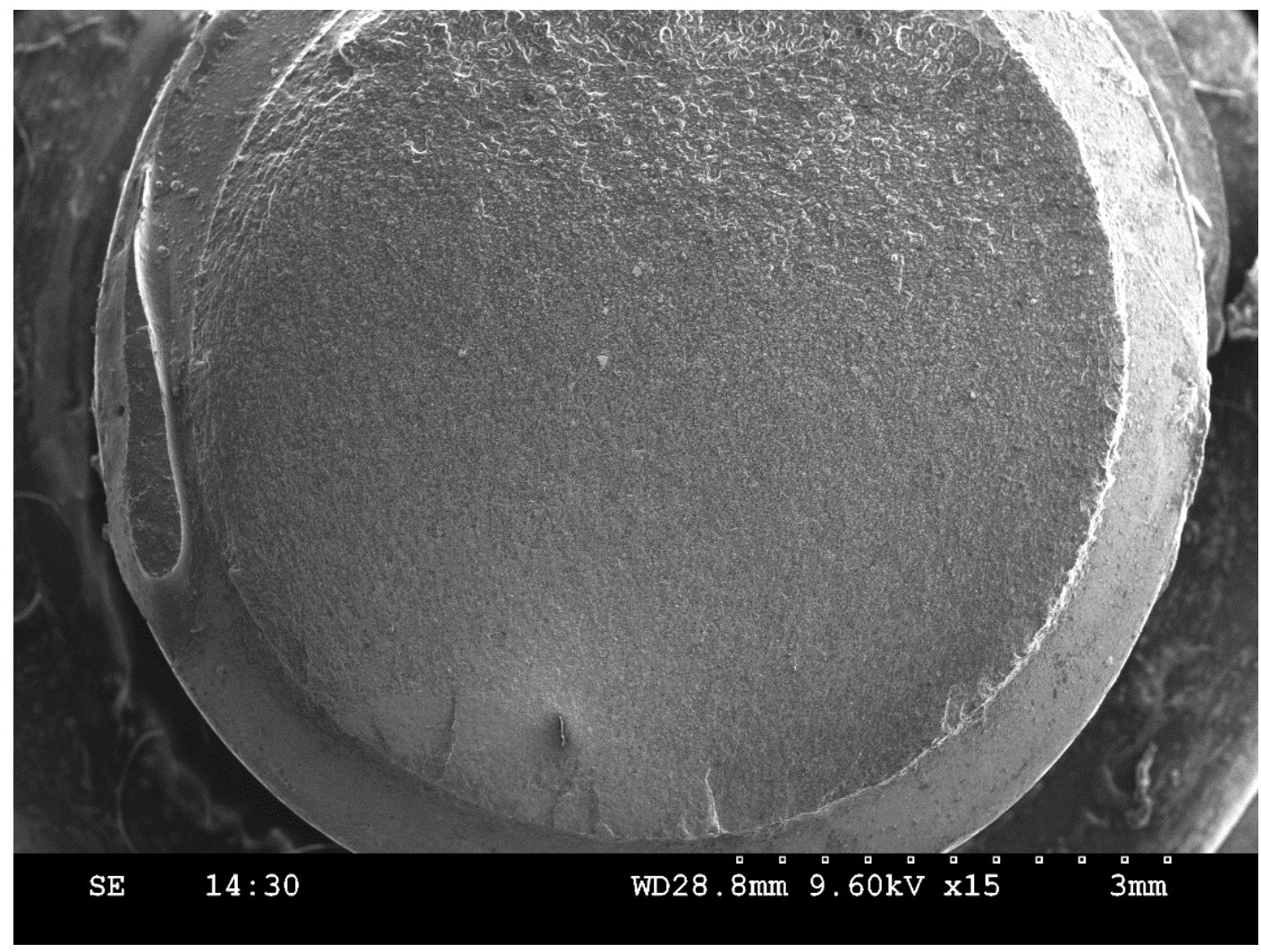

Fig. 3. General view of the crack of the bolt.

According to the performed fractographic analysis, it was found that the propagation of cracks in the stud bolt material was characterised by the formation of fatigue damage mesolines. The distance between fatigue damage mesolines generally increases, which characterises an increase in the crack growth rate as its length increases (the area of fatigue damage).

Destruction is multi-focal (Figs. 3-6). 


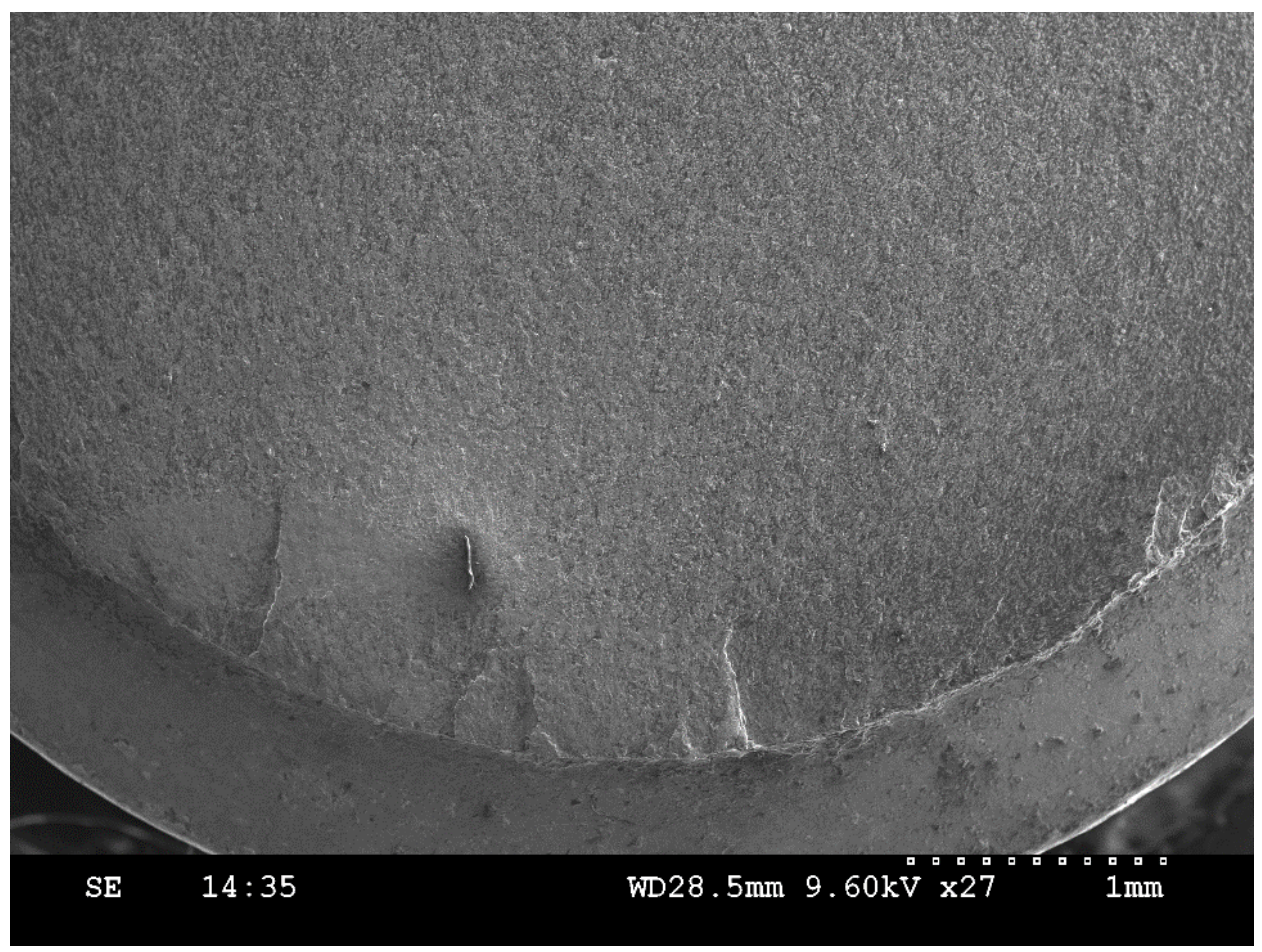

Fig. 4. Focal zone of the bolt.

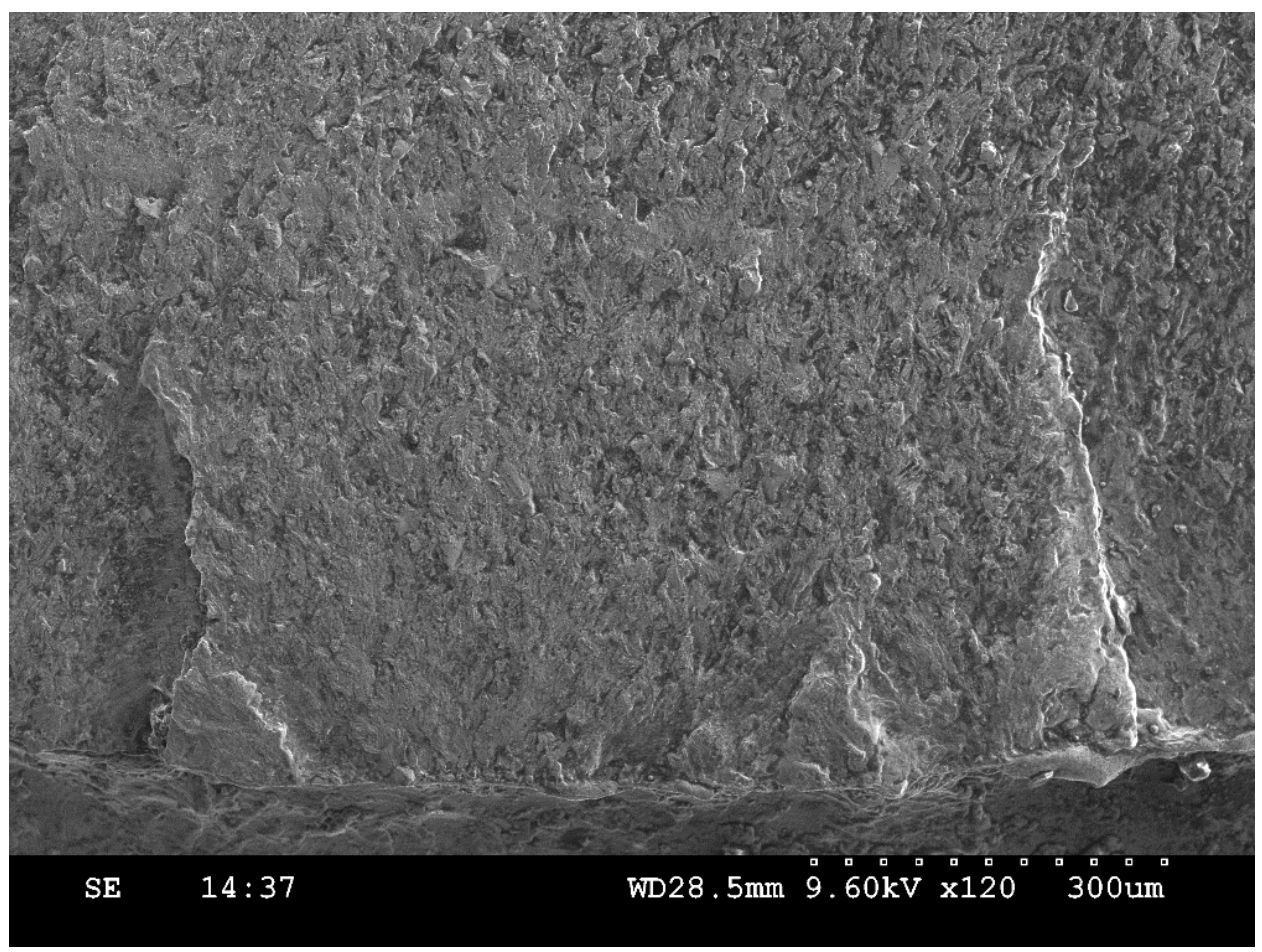

Fig. 5. Focal zone of the bolt. 


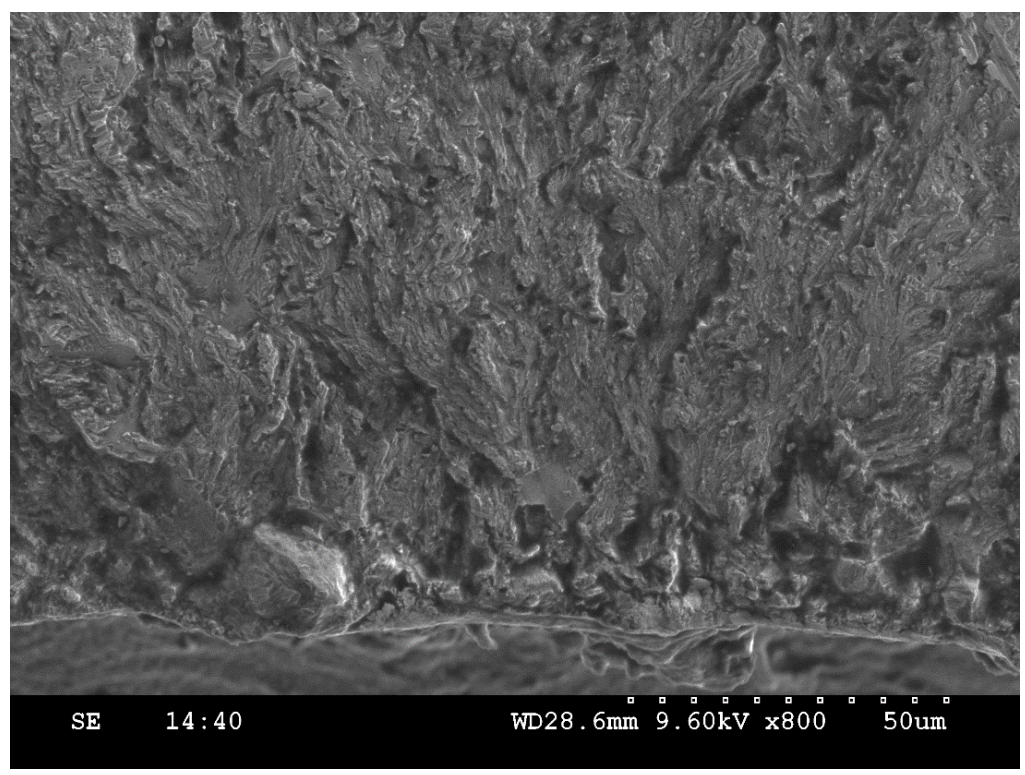

Fig. 6. The main nucleaus of the bolt.

Estimation of the length of a crack in a fracture of a bolt, respectively $\mathrm{L}_{1}$ (the distance from the origin of the source to the current position of the front crack propagation, $\mu \mathrm{m}$ ), and the speed of its propagation $V_{\mathrm{L} 1}(\mu /$ cycle $)$ was performed with respect to micro cracks nucleated from the main nucleus (hereinafter in the notation $\mathrm{L}_{\mathrm{i}}$, the index i corresponds to the crack number).

The microfractograms of the surface of the fracture fatigue zone, obtained by scanning with a SEM HITACHI-S300 N scanning electron microscope at different

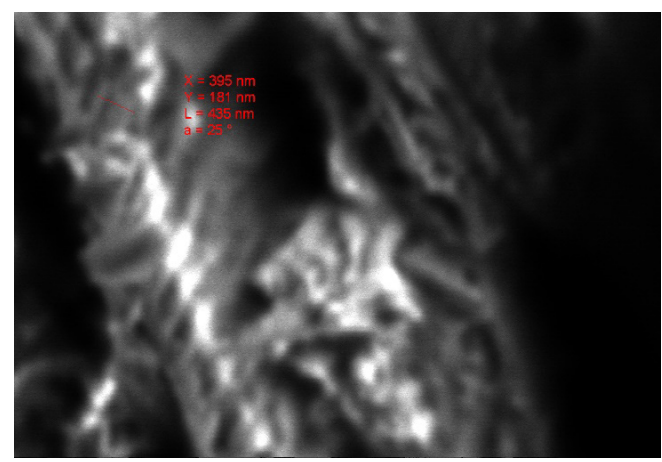

Fig. 7. Electronic microfractogram of crack No. 1, crack length $\mathrm{L}_{1}=0.04 \mathrm{~mm}$, average mesoline pitch $\mathrm{h}=145 \mathrm{~nm} /$ cycle. distances from the focus of the fatigue fracture, are shown in Figs. 7-19 for the main crack No. 1 with its length of $0.04 \mathrm{~mm}$ to achieve the length of $3.5 \mathrm{~mm}$.

In the structure of crack fracture fatigue damage mesolines are observed reflecting the kinetics of fatigue crack propagation at regular loading of object bench tests. The mesoline pitch is associated with the propagation velocity of the fatigue crack in the bolt material as a change in the position of its front by the value of this step in one loading cycle.

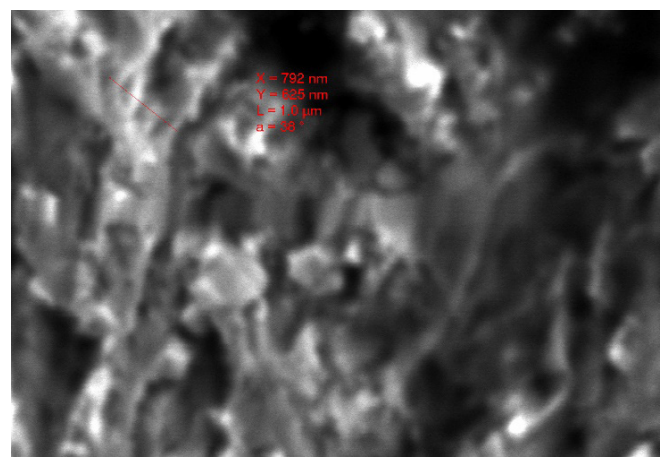

Fig. 8. Electronic microfractogram of crack No. 1; crack length $\mathrm{L}_{1}=0.08 \mathrm{~mm}$, average mesoline pitch $\mathrm{h}=250 \mathrm{~nm} /$ cycle. 


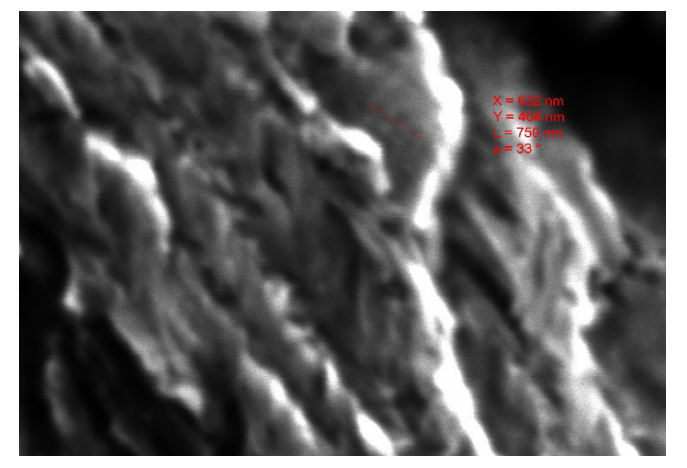

Fig. 9. Electronic microfractogram of crack No. 1; crack length $\mathrm{L}_{1}=0.27 \mathrm{~mm}$, mesoline pitch $\mathrm{h}=188 \mathrm{~nm} /$ cycle.

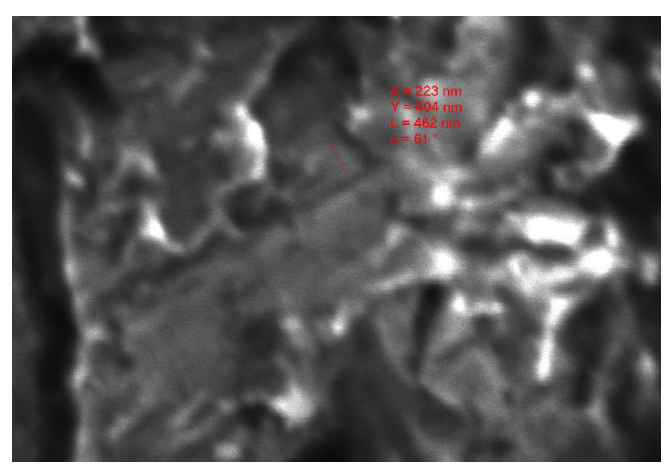

Fig. 11. Electronic microfractogram of crack No. 1; crack length $\mathrm{L}_{1}=0.60 \mathrm{~mm}$, average mesoline pitch $\mathrm{h}=155 \mathrm{~nm} /$ cycle.

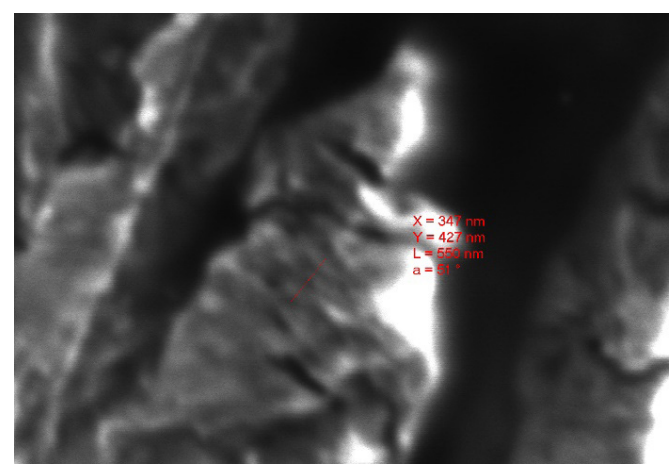

Fig. 13. Electronic microfractogram of crack No. 1; crack length $\mathrm{L}_{1}=0.95 \mathrm{~mm}$, average mesoline pitch $\mathrm{h}=185 \mathrm{~nm} /$ cycle.

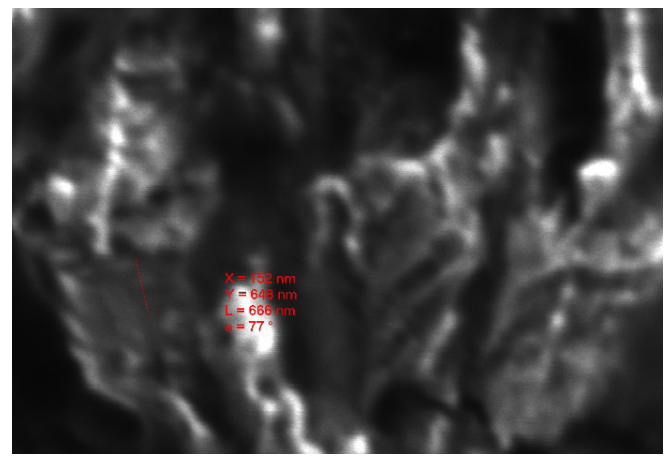

Fig. 10. Electronic microfractogram of crack No. 1; crack length $\mathrm{L}_{1}=0.33 \mathrm{~mm}$, average mesoline pitch $\mathrm{h}=222 \mathrm{~nm} /$ cycle.

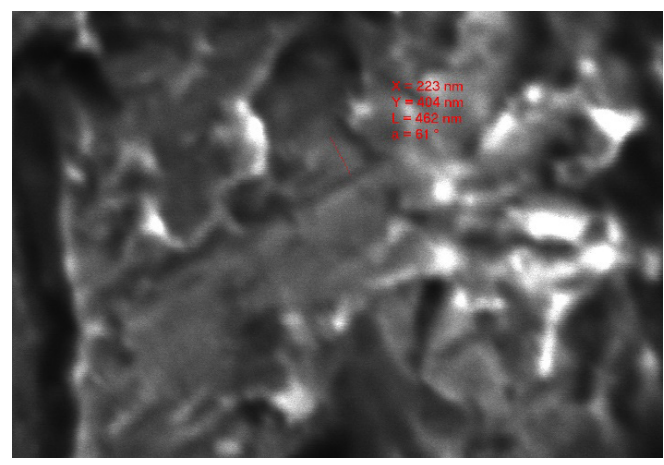

Fig. 12. Electronic microfractogram of crack No. 1; crack length $\mathrm{L}_{1}=0.65 \mathrm{~mm}$, average mesoline pitch $\mathrm{h}=188 \mathrm{~nm} /$ cycle.

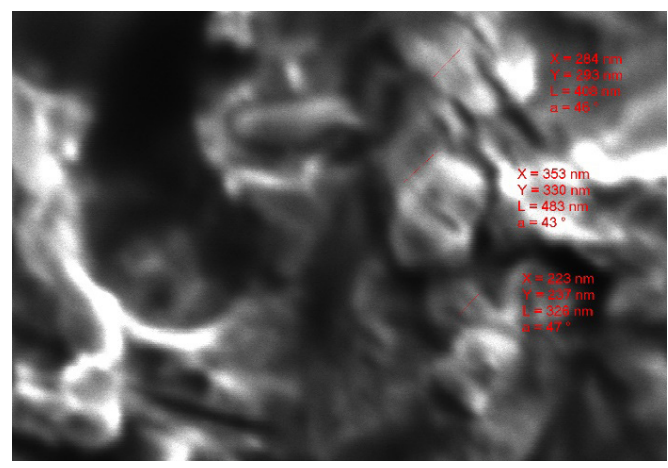

Fig. 14. Electronic microfractogram of crack No. 1; crack length $\mathrm{L}_{1}=1.40 \mathrm{~mm}$, average mesoline pitch $\mathrm{h}=153 \mathrm{~nm} /$ cycle. 


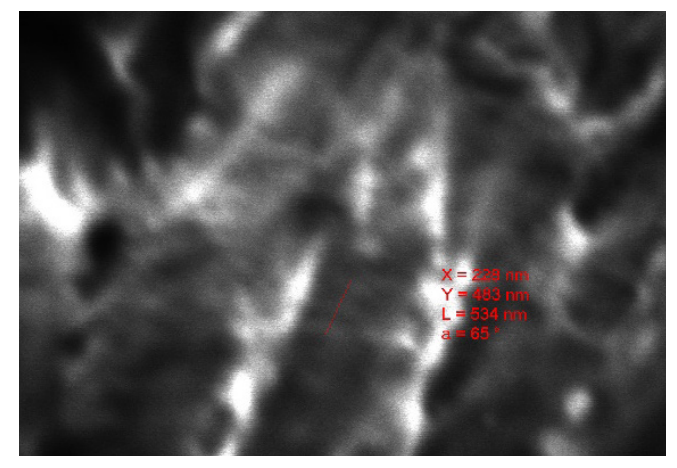

Fig. 15. Electronic microfractogram of crack No. 1; crack length $\mathrm{L}_{1}=1.44 \mathrm{~mm}$, average mesoline pitch $\mathrm{h}=178 \mathrm{~nm} /$ cycle.

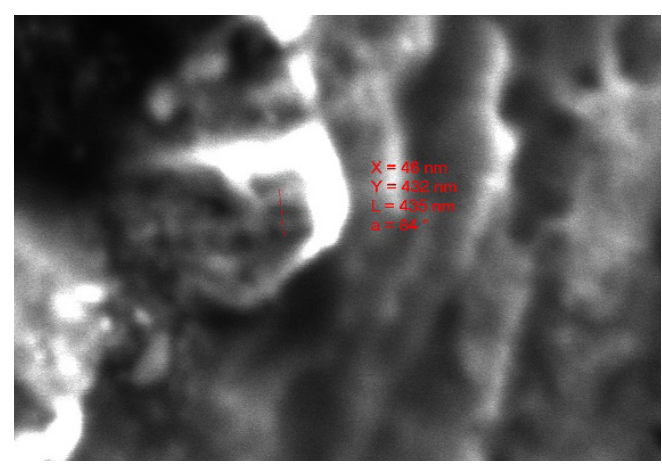

Fig. 17. Electronic microfractogram of crack No. 1 ; crack length $\mathrm{L}_{1}=2.50 \mathrm{~mm}$, average mesoline pitch $\mathrm{h}=218 \mathrm{~nm} /$ cycle.

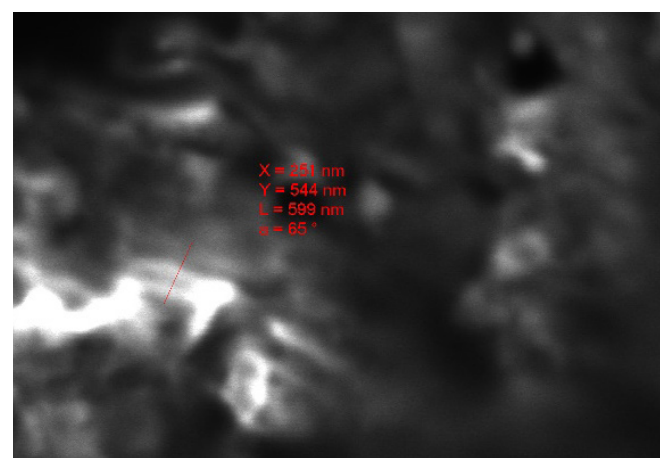

Fig. 19. Electronic microfractogram of crack No. 1; crack length $\mathrm{L}_{1}=3.50 \mathrm{~mm}$, average mesoline pitch $\mathrm{h}=200 \mathrm{~nm} /$ cycle.

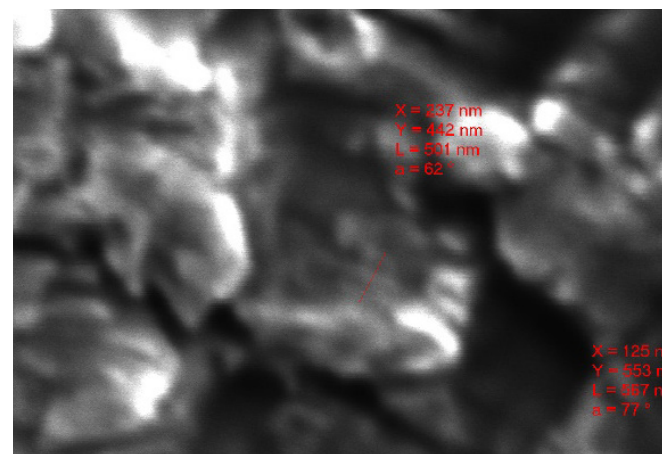

Fig. 16. Electronic microfractogram of crack No. 1; crack length $\mathrm{L}_{1}=2.00 \mathrm{~mm}$, average mesoline pitch $\mathrm{h}=178 \mathrm{~nm} /$ cycle.

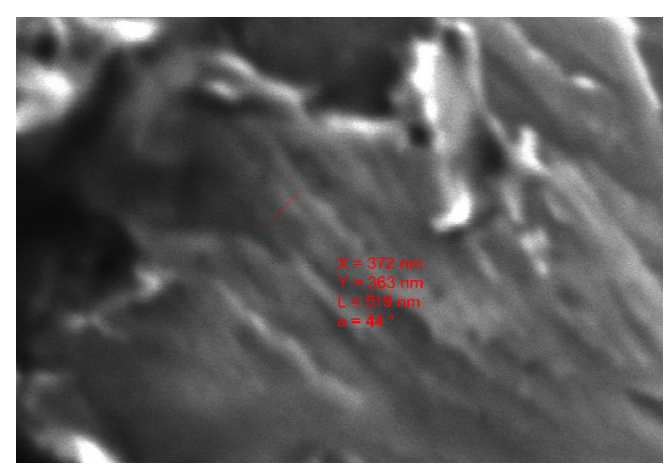

Fig. 18. Electronic microfractogram of crack No. 1; crack length $\mathrm{L}_{1}=3.00 \mathrm{~mm}$, average mesoline pitch $\mathrm{h}=173 \mathrm{~nm} /$ cycle. 
The results of measurements of the length of the fatigue crack in the fracture of the stud bolt, the mesoline pitch as they develop from the fracture centre to the length $\mathrm{L}_{1}$, respectively, as well as the calculation results of additional parameters are presented in Table 1.

Table 1. The Results of Fractographic Assessment of the Velocity $\mathrm{V}_{\mathrm{L} 1}$ and the Growth Period of Fatigue Crack No. 1

\begin{tabular}{|c|c|c|c|c|c|c|}
\hline No. & $\begin{array}{l}\mathrm{L}_{1} \\
\mathrm{~mm}\end{array}$ & $\begin{array}{c}V_{\mathrm{Ll}}, \\
\mu / \text { cycle }\end{array}$ & $\begin{array}{c}1 / V_{\mathrm{L} 1} \\
\text { cycle/ } / \mu\end{array}$ & $\begin{array}{l}\Delta \mathrm{N}_{\mathrm{i}}, \\
\text { cycle }\end{array}$ & $\begin{array}{l}\mathrm{N}_{\mathrm{CRi}} \text {, } \\
\text { cycle }\end{array}$ & $\begin{array}{l}\mathrm{N}_{1} \text {, } \\
\text { cycle }\end{array}$ \\
\hline 1 & 0.04 & 0.145 & 6.897 & 276 & 276 & 15353 \\
\hline 2 & 0.08 & 0.250 & 4.000 & 160 & 436 & 15513 \\
\hline 3 & 0.27 & 0.188 & 5.333 & 1013 & 1449 & 16526 \\
\hline 4 & 0.33 & 0.222 & 4.505 & 270 & 1719 & 16797 \\
\hline 5 & 0.60 & 0.155 & 6.452 & 1742 & 3461 & 18539 \\
\hline 6 & 0.65 & 0.128 & 7.813 & 391 & 3852 & 18929 \\
\hline 7 & 0.95 & 0.185 & 5.405 & 1622 & 5474 & 20551 \\
\hline 8 & 1.40 & 0.153 & 6.536 & 2941 & 8415 & 23492 \\
\hline 9 & 1.44 & 0.178 & 5.618 & 225 & 8640 & 23717 \\
\hline 10 & 2.00 & 0.178 & 5.618 & 3146 & 11786 & 26863 \\
\hline 11 & 2.50 & 0.218 & 4.598 & 2299 & 14084 & 29162 \\
\hline 12 & 3.00 & 0.173 & 5.780 & 2890 & 16975 & 32052 \\
\hline 13 & 3.50 & 0.200 & 5.008 & 2504 & 19479 & 34556 \\
\hline
\end{tabular}

Plotting crack growth diagrams and determining their growth rate on the polished surface of the sample, the moment when a crack appeared was clearly visible with a microscope. During the tests, after a certain number of loading cycles, the crack size $L_{1}$ was measured on the front surface of the specimen.

The results of such measurements were used to construct the crack growth diagrams in the $V_{\mathrm{L}}$; L axes, i.e., dependence of the crack length on the crack growth rate, measured in increment of crack length per loading cycle. The rate of growth of fatigue cracks was determined by graphical differentiation of these diagrams. The most convenient is the scheme for determining the rate of crack growth using a graphical editor (Fig. 20).

In the calculation of fatigue crack growth rate $V_{\mathrm{L} 1}$ by the number of mesolines and the mesoline pitch where crack No. 1 had reached length of $\mathrm{L}_{1}=0.04 \mathrm{~mm}$, mesoline pitch was assumed with reference to the average pitch, recorded in its length, which corresponds to $\mathrm{L}_{1}=0.04 \mathrm{~mm}$ (see Table 1).

Graphs of kinetic dependences $V_{\mathrm{L}}=\mathrm{f}$ (L) and crack growth curves $\mathrm{L}=\mathrm{f}(\mathrm{N}) \quad(\mathrm{N}$ is the current operating time during bench tests) are shown in Figs. 20 and 21. 


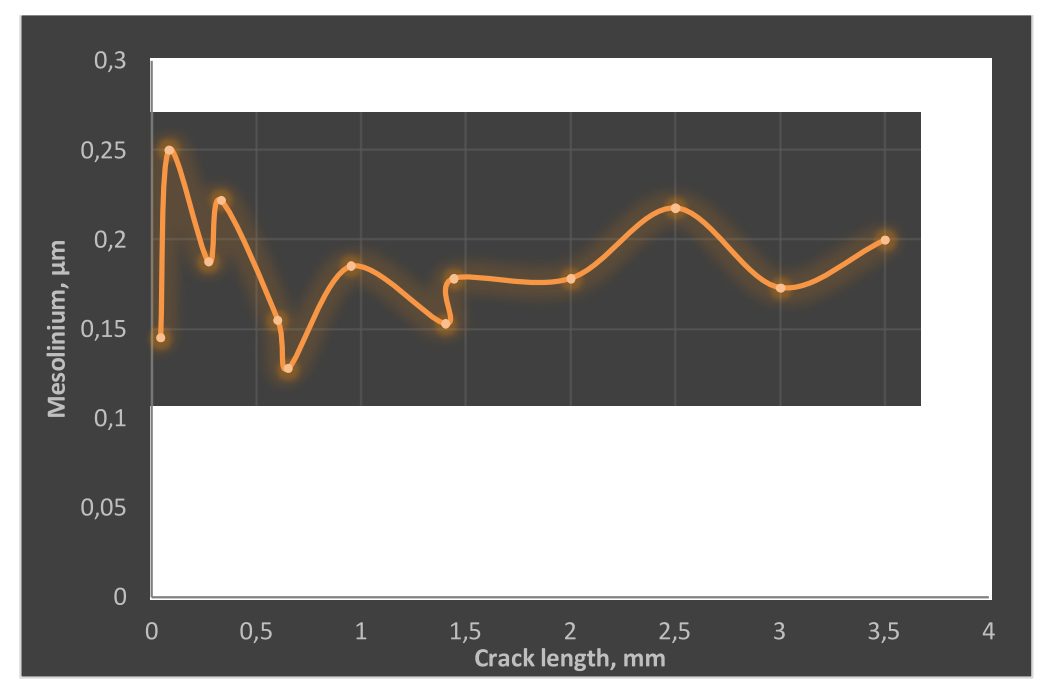

Fig. 20. Crack growth rate $V_{\mathrm{L} 1}$ of its length $\mathrm{L}_{1}$, respectively.

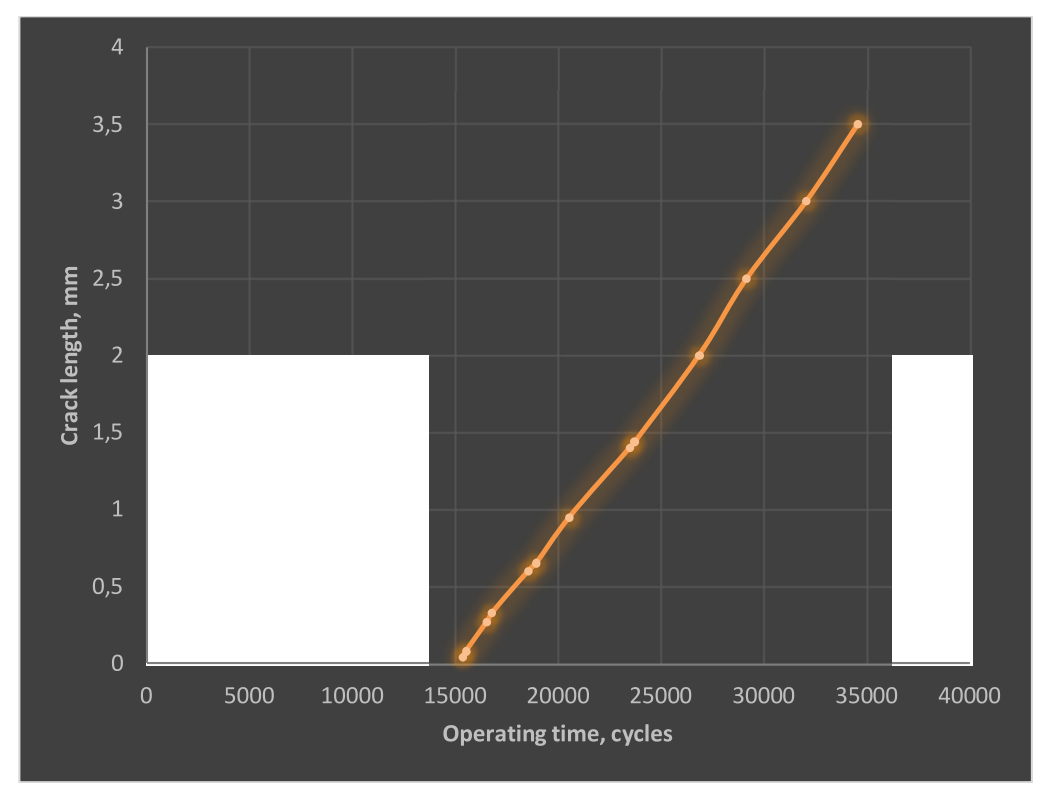

Fig. 21. The dependence of the length of the fatigue crack $\mathrm{L}_{1}$ on the current operating time during testing.

The presented study was based on the methodicalapproach given in sources [7]-[9]. It should also be noted that the above estimate of the crack growth period is based on measurements of local velocities having a stochastic nature; therefore, the accuracy of the estimation of the crack growth period depends on the frequency of velocity measurements [10]. Taking into account the number of measurements performed in this study, the error in estimating the crack growth period with a probability of $90 \%$ does not exceed $\pm 12 \%$.

In this way, fatigue crack in the material 
of the bolt length of 0 and $0.4 \mathrm{~mm}$ with a probability of $90 \%$ was formed with an operating time of $15353 \pm 2337$ loading cycles.

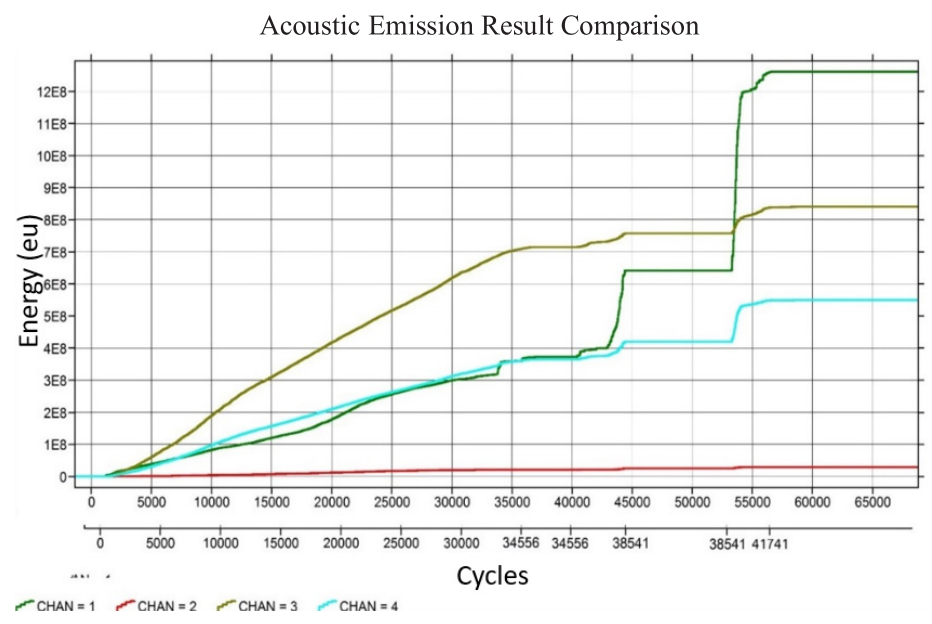

Fig. 22. The total energy of the acoustic emission signal on the last day of testing (lower scale - reduced loading cycles).

\section{DISCUSSION}

In order to cope with vessel equipment reliability, engineering designers rely heavily on the regulations prescribed by the classification societies. Classification societies' rules are based on a wide knowledge collected over hundreds of years and are mostly based on simplified, empirical equations. However, not all the problems occurring on modern ships can be successfully solved using this approach. To properly address issues of marine structural failures, engineers need to turn to failure analysis databases and, learning from the findings, improve procedures for ship designing.

Reviewing case studies, one can notice that most of them use solely experimental approaches in finding the causes of failures. Techniques such as NDT inspection, microscopy or crystallography are used to determine the origin of failures. Only a few studies use numerical analysis as a supplement to traditional experimental techniques applied in the field of failure analysis.

However, those who do combine experimental and numerical approaches tend to present more reliable results and go a bit further than usual failure analysis does they suggest modifications to engineering design. Thus, a combination of failure analysis and design optimization is arising here.

The following points must be considered when checking the connecting rod stud bolt for re-use or replacement. If problems enlisted below are not acknowledged at the first opportunity, they may increase the risk of crack development of connecting rod bolts [11].

Problem requiring design optimization (Not objective of the research) No. 1. In some cases, during inspections, a small gap between the connecting rod bolt head and the connecting rod itself is identified in the assembled condition with fully tightened connecting rod bolts.

On some affected connecting rods, a 
feeler gauge with up to $0.4 \mathrm{~mm}$ thickness could be introduced between bolt head and connecting rod (see Fig. 23) [12].

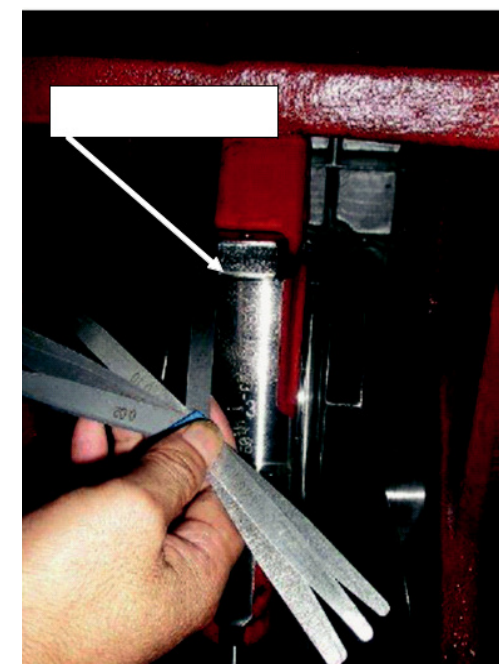

Fig. 23. Introduction of feeler gauge between connecting rod bolt head and connecting rod.

For correct loading of the connecting rod bolt, no gap is admissible. After correct assembly and tightening of the bolt, the connecting rod bolt has to rest without any gap on the connecting rod.

The investigation of the above cases has revealed that the chamfer of the connecting rod bolt bore was not machined properly so that the bolt was partly resting on the chamfer instead of the proper contact area under the bolt head (see Figs. 24 and 25).

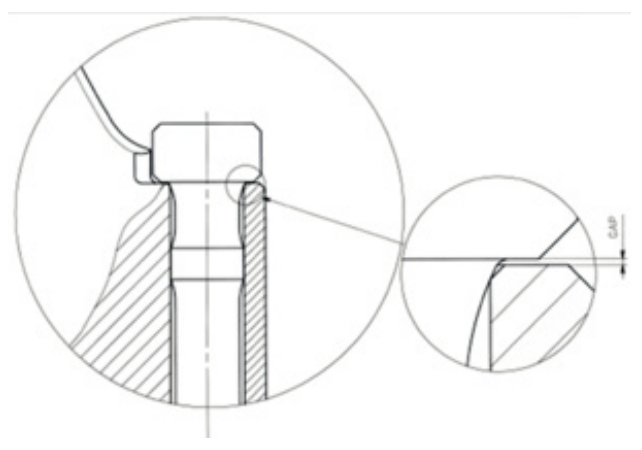

Fig. 24. Improper seat of the bolt on mismachined chamfer.

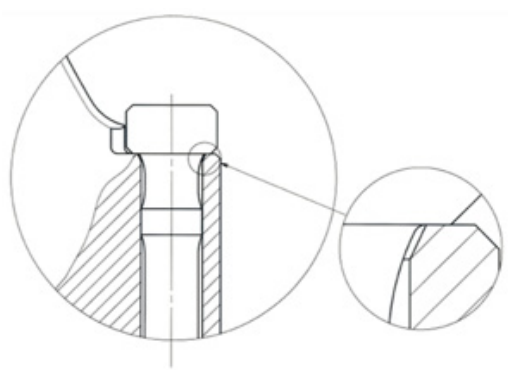

Fig. 25. Proper seat of the bolt on the contact surface under the bolt head.

In a worst-case scenario, such a gap between connecting rod bolt and connecting rod may lead to a plastic deformation (adaption) between bolt radius and mismachined chamfer during engine operation. This, with a certain setting of the bolt, may cause a partial loss of pretensioning of the connecting rod bolt.

Impact on engine: Unfortunately, based on the information available, it could not be excluded that GenSets are affected in a way that some connecting rods may show such a mismachined chamfer.

Measures recommended by MAN Diesel: Fortunately, the inspection procedure is very easy and this inspection should be accomplished according to MAN Service Letter SL08-500/JNN.

Problem requiring design optimization (Not objective of the research) No. 2. Elongation of hydraulically tightened bolts. The elongation measurement is introduced to reduce possible failures in connection with hydraulic tightening of bolts such as:

- Insufficient hydraulic pressure;

- Missing pressure at one or more hydraulic jacks due to incorrect fixing of hydraulic snap coupling at the hose connection[13].

With the introduction of elongation measurement, the elongation of each bolt is monitored during the tightening process and hereby it is possible to determine if the correct hydraulic pressure has been applied to each bolt. 
The tightening procedure with elongation measurement is performed according to MAN Service Letter SL2018-656/JNN.

By introducing the elongation measurement, the retightening procedure is changed after overhaul as follows:

- Without elongation measurement: Retightening after 200 running hours.

- With elongation measurement:

Retightening after starting up the engine, but before any load has been applied.

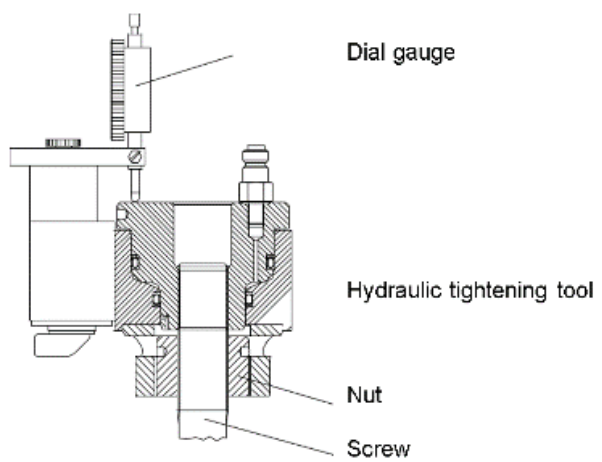

Fig. 26. Measuring tool, 1 pc hydraulic jack will be needed.

Problem requiring design optimization (Not objective of the research) No. 3 . Fretting on connecting rod contact surface (see Fig. 23).

Depending on the engine type, the connecting rod itself consists of three different main parts which are tightened together with bolts. Due to operating forces, those connections as well as the part itself, are subjected to high load. Every connection fulfils high requirements towards mechanical load. Micro-movements between two parts under high load can in single cases lead to fretting marks. If those fretting marks are not grinded and smoothened at the first opportunity, they may increase the risk of crack development. To avoid a damage caused by fretting marks, we released precautions and countermeasures [14].

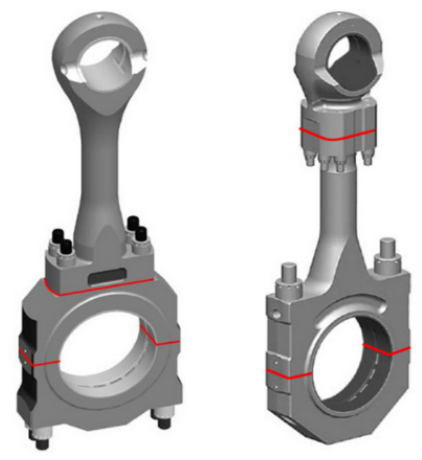

Fig. 27. Connecting rod contact surface.

Measures: To prevent dynamically loaded contact surfaces from fretting, certain preconditions have to be fulfilled. Every unevenness or deviation from the flat machined surface has to be precisely eliminated. Afterwards, during assembling, the surface has to be clean, dry and absolutely free of oil, grease or other fluids. To ensure a proper condition of each connecting rod part and a high operating reliability, all contact surfaces have to be checked and, if necessary, grinded and magnetically crack tested.
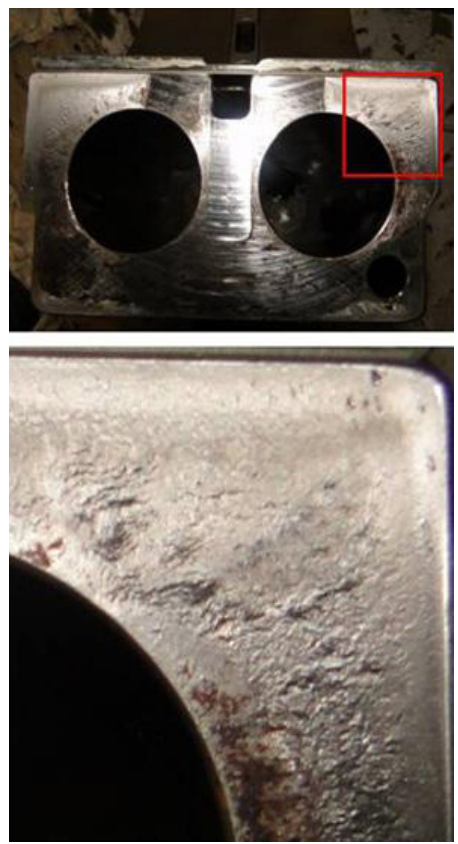

Fig. 28. Fretting on a connection surface. 


\section{CONCLUSION}

In this paper, recent ship engine incident has been outlined to learn about connecting rod bolt failure nature. Unfortunately, this study is not able to affect the industry, and similar failures are still observed.

The research successfully proved that there were clear signs of fatigue and no other destructive forces that could cause the engine to collapse.

The study allowed concluding that a fracture in the material of bolt No. 7 in the diesel engine connecting rod stud is fatigue and the destruction is multi-focal.

The results of fractographic studies made it possible to determine the moments of nucleation of cracks in the frac- tures of the bolt material: a fatigue crack in the material of a bolt with a length of 0.04 $\mathrm{mm}$ with a probability of $90 \%$ was formed with a bench operating time of $15353 \pm$ 2337 loading cycles.

Particularly, to avoid future failures, the design optimization can be considered as a solution as described in the discussion paragraph.

It is strongly recommended as good engineering practice to replace diesel engine connecting rod stud bolt in every main overhaul due to possibility of bolt fatigue crack development during next service period and, as a result, expensive breakdown may occur.

\section{ACKNOWLEDGEMENTS}

The research has been supported by the Latvian Science Council. Project "Development of Smart Technologies for Efficient and
Reliable Waterborne Operations". (STEEWO) (No. LZP-2019/1-0478).

\section{REFERENCES}

1. Gasparjans, A., Terebkovs, A., \& Ziravecka, A. (2017). Application of resonance method for examining of piston ring technical condition. In 16th International Scientific Conference (pp. 884-891), 24-26 May 2017, Jelgava, Latvia (Elsevier SCOPUS, Thomson Reuters Web of Science, AGRIS, EBSCO Academic Search Complete, Agricola).

2. Gasparjans, A., Terebkovs, A., \& Ziravecka, A. (2019). Theoretical and experimental analysis of technical condition of piston rings of vessel diesel installations by method of resonance oscillations. In 18th International Scientific Conference (pp. 1287-1294), 22-24 May 2019, Latvia University of Agriculture Faculty of Rural
Engineering, Jelgava, Latvia. doi: 10.22616/ ERDev2019.18.

3. Pastorcic, D., Vukelic, G., \& Bozic, Z. (2019). Coil Spring Failure and Fatigue Analysis. Eng. Fail. Anal., 1 (99), 310-318.

4. Lukacs, J. (2019). Fatigue Crack Propagation Limit Curves for High Strength Steels Based on Two-Stage Relationship. Engineering Failure Analysis, 431-442.

5. Cui, W. A (2002). State-of-the-Art Review on Fatigue Life Prediction Methods for Metal Structures. Journal of Marine Science and Technology, 7 (1), 43-56.

6. Schijve, J. (1979). Four Lectures on Fatigue Crack Growth. Engineering Fracture Mechanics, 169-181. doi:10.1016/00137944(79)90039-0. ISSN 0013-7944. 
7. Shaniavsky, A. A. (2003). Safe fatigue failure of aircraft structural elements. Ufa: Publishing house of scientific and technical literature "Monograph".

8. Stoyda, Yu.M. (1988). The Development of the Method of Quantitative Fractography and the Study of Cyclic Crack Resistance of Structural Elements from Aluminium Alloys. The Doctoral Thesis. Moscow: VIAM.

9. Guide for Designers (RDK). (1980). Aircraft Strength (vol. 3), Fatigue Strength, Resource and Reliability of an Aircraft (book 4), Determination by the Method of Fractography of the Growth Duration of Fatigue Cracks in the Structural Elements of an Airframe (issue 12). M. Ed. Department of TsAGI.

10. Urbahs, A., \& Carjova, K. (2018) Research on the Bolting Elements of Helicopter Fuselage and Tail Boom Joints Using Acoustic Emission Amplitude and Absolute Energy Criterion. American Journal of Aerospace Engineering, 32 (3). https://doi.org/10.1061/ (ASCE)AS.1943-5525.0000963
11. Vizentin, G. (n.d.). Marine Propulsion System Failures - A Review. Available at https://www.mdpi.com/2077-1312/8/9/662/ htm

12. MAN Service Letter SL08-500/JNN, MAN Diesel

13. MAN Service Letter SL2018-656/JNN, MAN Diesel

14. MAN Diesel \& Turbo. (2015). PrimeServ Customer Information No. 348 / June 2015. Available at https://primeserv.man-es. com/docs/librariesprovider5/service-lettermarine/pci-348.pdf?sfvrsn=1cdb3fa2_4 